\title{
Impact of temperature increase on performance of $k$ harif rice at Kalyani, West Bengal using WOFOST model
}

\author{
RIA BISWAS ${ }^{* *}$, SAON BANERJEE ${ }^{2}$ and BANJUL BHATTACHARYYA ${ }^{1}$ \\ ${ }^{1}$ Department of Agricultural Statistics, ${ }^{2}$ Department of Agril. Meteorology and Physics, \\ BCKV, Mohanpur, Nadia, PIN: 741235, West Bengal, India. \\ *Corresponding Author: E-mail: ria.biswas6@gmail.com
}

\begin{abstract}
WOFOST model (version 7.1.2) was used to study the impacts of elevated thermal environment on kharif rice at Kalyani situated in lower Gangetic region of West Bengal. The model was calibrated and validated with experimental data collected during kharif season of 2010 to 2013. The simulated yield data was well matched with actual data. The sensitivity analysis for effect of temperature change on crop maturity showed that if temperature was increased by $1^{\circ} \mathrm{C}$ and $2^{\circ} \mathrm{C}$ the maturity period was delayed by 3 and 7 days respectively. The range of simulated yield was $3150 \mathrm{kgha}^{-1}$ to $5046 \mathrm{~kg} \mathrm{ha}^{-1}$ whereas the actual yield in the experimental field ranged from $2907 \mathrm{~kg} \mathrm{ha}^{-1}$ to $5495 \mathrm{~kg} \mathrm{ha}^{-1}$. The model shows 96 per cent accuracy to predict rice yield with $\mathrm{R}^{2}$ value 0.82 and RMSE value 337.87 . It was also observed that the sowing should be done before $15^{\text {th }}$ July to obtain higher yield of kharif rice in the study region.
\end{abstract}

Key words: Crop simulation model, WOFOST, kharif rice, yield, temperature

Crop growth is an extremely complex phenomenon with complicated interactions of soil, plant and weather conditions. Climate changes have a great impact on agricultural production. The impact of weather variables on the entire crop growth period can be best represented by crop-weather models which facilitate the relationship between weather, soil, climate and crop yield.

Crop growth simulation model can be used to evaluate key interactions quickly and identify traits with the greatest impact on yield potential and for assessing the relationships between crop productivity and environmental factors (Aggarwal et al., 1997). Simulation has been used extensively to assess impacts of climate change on yield and to find out the suitable adaptation options at a specific region. The integration of climate and geo-spatial soil databases allows the user a wide range of crop management options for simulation and analysis.

WOFOST (WOrld FOod STudies) is a computer model that simulates the daily growth of a specific crop, given the selected weather and soil data. In WOFOST, only ecological factors are considered under the assumption that optimum management practices are applied. This model has been used by various workers for sensitivity analysis in wheat (Mishra et al. 2015), spatial wheat yield prediction (Chaudhari et al. 2010) and for comparing with ORYZA
2000 model for rice crop (Mukherjee et al. 2011).

Considering the background, the present research work aims at to simulate the kharif rice yield through WOFOST model and to study the impact of elevated temperature on performance of rice.

\section{MATERIALS AND METHODS}

\section{Model inputs data}

As per the input-requirements of WOFOST Model (Boogaard et al., 1998), secondary information on yield and yield attributes were collected from AICRP on Agrometeorology Reports of Mohanpur Centre, BCKV for the period of 2010 to 2013 (AICRPAM, 2010-13). Information on IET4786 (Shatabdi) variety of rice was considered which is the most popular variety of the study region. Weather data, namely, maximum temperature, minimum temperature, bright sunshine hours, rainfall, wind speed and relative humidity were collected from Kalyani Meteorological Observatory (Latitude-22 ${ }^{0} 572$ North and Longitude $88^{\circ} 202$ East). Data on soil characteristics were collected from available report of FASAL Project, Kalyani Cenre (FASAL, 2013).

\section{Evaluation of the model}

The performance of the model was evaluated through 
Table 1: Calculated genetic coefficient forShatabdi variety generated through iteration method

\begin{tabular}{lll}
\hline Genetic coefficient & Code used in WOFOST model & Value \\
\hline Optimum day-length for development & DLO & 10.5 hours \\
Temperature sum from emergence to anthesis & TSUM1 & 1723 degree cel \\
Temperature sum from anthesis to maturity & TSUM2 & 526 degree cel \\
Initial total crop dry weight & TDWI & $50.00 \mathrm{~kg} \mathrm{ha}^{-1}$ \\
Efficiency of conversion into leaves & $\mathrm{CVL}$ & $0.754 \mathrm{~kg} \mathrm{~kg}^{-1}$ \\
Efficiency of conversion into storage organ & $\mathrm{CVO}$ & $0.600 \mathrm{~kg} \mathrm{~kg}^{-1}$ \\
Efficiency of conversion into roots & $\mathrm{CVR}$ & $0.754 \mathrm{~kg} \mathrm{~kg}^{-1}$ \\
Efficiency of conversion into stems & $\mathrm{CVS}$ & $0.754 \mathrm{~kg} \mathrm{~kg}^{-1}$ \\
\hline
\end{tabular}

some statistical parameters, namely, coefficient of determination $\left(\mathrm{R}^{2}\right)$, root mean square error (RMSE) and others (Fox, 1981). The accuracy and bias were calculated as per standard formula (Banerjee et al., 2014).

\section{Impact studies}

For the study region the temperature may increase from $1^{\circ} \mathrm{C}$ for next decade to $3^{\circ} \mathrm{C}$ at the end of the century (Boomiraj et al., 2010). Considering these projections, the impact of $1^{\circ} \mathrm{C}$ and $2^{\circ} \mathrm{C}$ temperature rise (above average temperature) on production of kharif rice has been assessed for Kalyani. The average weather data of Kalyani Observatory for the period of 1980 to 2010 was considered as the normal weather data and the average temperature for the said period is termed as AT in this paper. The crop performance was assessed under normal weather condition as well as elevated temperature. $1^{\circ} \mathrm{C}$ and $2^{\circ} \mathrm{C}$ were added with both maximum and minimum average temperature (AT) to obtain elevated temperature regime. This regime was used as 'input weather file' of the WOFOST model to assess the impact.

\section{RESULT AND DISCUSSION}

\section{Calibration and validation of WOFOST model}

The pre-calibrated WOFOST model (version 7.1.2) for 'Shatabdi' variety was used in the present study. Simple iteration method (i.e. trial and error method) was used to modify the coefficient related to phenological aspect and crop growth parameter. The evaluated genetic coefficients are summarized in Table 1.

For validation of WOFOST model, the grain yield production data were compared with model output. The wide range of date of transplanting was considered to thoroughly evaluate the model to simulate yield.

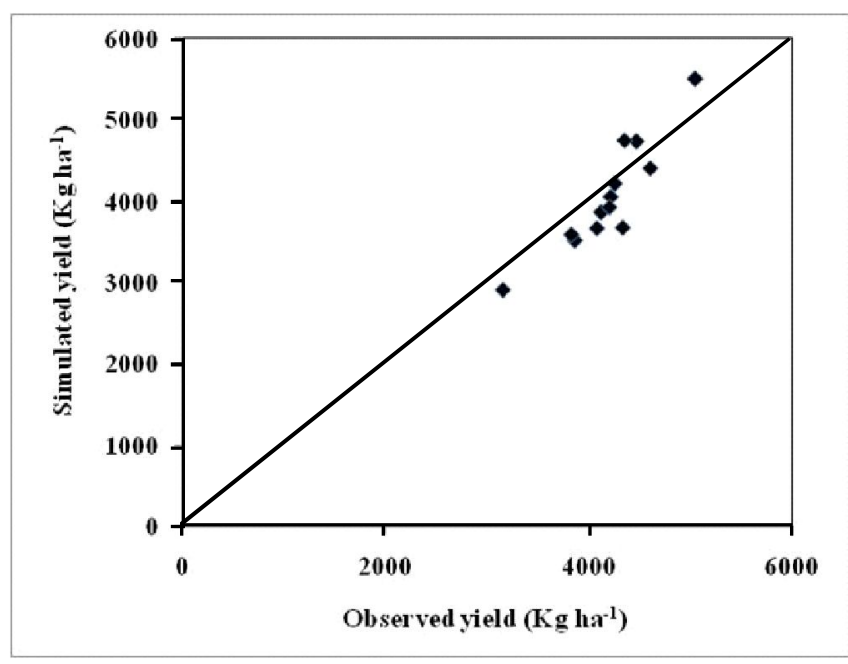

Fig. 1: Relationship between observed and simulated yields of kharif rice shown through 1:1 line (Bias= $134.84, \mathrm{R}^{2}=0.82, \mathrm{RMSE}=337.87$, Accuracy $\%=$ 96.67)

Fig. 1 shows the relationship of simulated yield against actual ones for Shatabdi.It is observed that the data points are very close to $1: 1$ line, hence the modeled grain yields matched well with actual experimental yields. The model shows 96 per cent accuracy to predict rice yield with $\mathrm{R}^{2}$ value of 0.82 and RMSE value of 337.87 .

\section{Predicting yield under elevated temperature}

Crop maturity period is highly dependent on prevailing temperature and crop duration decreases with the temperature enhancement. The effect of increased minimum temperature has pronounced impact on grain yield. Shah et al., (2011) also emphasized on adverse impact of higher temperature on yield of rice. The maturity period of Shatabdi variety was reduced by 3 to 7 days due to $1-2^{\circ} \mathrm{C}$ temperature enhancement. The model output also showed the simulated LAI would decrease with increase of temperature. During PI 
Table 2: Performance of rice under elevated thermal condition

\begin{tabular}{llll}
\hline & $\mathrm{AT} *$ & $\mathrm{AT}+1^{\circ} \mathrm{C}$ & $\mathrm{AT}+2^{\circ} \mathrm{C}$ \\
\hline LAI at Panicle Initiation stage & 6.1 & 5.5 & 4.4 \\
LAI at grain filling stage & 7.2 & 6.9 & 5.8 \\
Days to mature & 110 & 107 & 103 \\
Reduction in days to maturity (days) & & 3 & 7 \\
Yield (kg ha-1) & 4238.6 & 4006.5 & 3784.2 \\
Yield reduction $(\%)$ & - & 5.5 & 10.7 \\
\hline
\end{tabular}

*Simulated yield considering average temperature (AT) and normal weather condition

and grain filling stages, the enhanced temperature effect on LAI would be more (Table 2). With the normal DOS ( $4^{\text {th }}$ week of May) and the common management practices, 5-10 per cent yield reduction would be observed with rise in temperature upto $2^{\circ} \mathrm{C}$. Under elevated thermal condition, the yield decrease occurs mainly due to the lower LAI throughout the crop growth stages and shorter crop growth period, which is evident from the study.

\section{REFERENCES}

Aggarwal, P.K., Kropff, M.J., Cassman, K.G and ten Berge, H.F.M. (1997). Simulating genotypic strategies for increasing rice yield potential in irrigated, tropical environments. Field Crops Res., 51:5-17.

AICRPAM (2010-13). Annual progress report of AICRP on Agro-meteorology of Mohonpur Centre, Directorate of Research, BCKV.

Banerjee S., Das S., Mukherjee A., Mukherjee A., Saikia B. (2014). Adaption strategies to combat climate change effect on rice and mustard in Eastern India, Mitig. Adapt. Strat. Glob. Change, DOI 10.1007/s11027-014-9595y.

Boogaard, H.L., Van Diepen, C.A., Rötter, R.P., Cabrera, J.M.C.A., Van Laar, H.H. (1998). User's guide for the WOFOST 7.1 crop growth simulation model and WOFOST control center 1.5. Technical Document 52, Winand Staring Centre, Wageningen, the Netherlands, $144 \mathrm{pp}$.
Boomiraj K., Chakrabarti B., Aggarwal P.K., Choudhary R., Chander S. (2010). Assessing the vulnerability of Indian mustard to climate change. Agric. Ecosys. Environ., 138: 265-273.

Chaudhari, K.N., Tripathi, R. and Patel, N.K. (2010). Spatial wheat yield prediction using crop simulation model, GIS remote sensing and ground observed data. $J$. Agrometeorol., 12(2):174-180.

FASAL (2013). Annual progress report of FASAL project of Kalyani centre, Directorate of Research, BCKV.pp 4

Fox, D.G. (1981). Judging air quality model performance: a summary of the AMS workshop on dispersion model performance.Bull. Am. Meteorol. Soc., 62: 599-609.

Mishra, S.K., Shekh, A.M., Pandey, V., Yadav, S.B. and Patel, H.R. (2015). Sensitivity analysis of four wheat cultivars to varying photothermal and temperature at different phenological stages using WOFOST model. $J$. Agrometeorol., 13(2):74-79.

Mukherjee, J., Singh, L., Singh, G., Bal, S.K., Singh, H. and Prabhjyot Kaur (2011). Comparative evaluation of WOFOST and ORYZA2000 models in simulating growth and development of rice (Oryza sativa L.) in Punjab. $J$. Agrometeorol., 13(2):86-91.

Shah, F., Huang, J., Cui, K., Nie, L., Shah, T., Chen, C., Wang, K., (2011). Impact of high-temperature stress on rice plant and its traits related to tolerance. J. Agric. Sci., 149: $545-556$. 